\title{
Application of Parallel Difference Tests to Resolve the Axial Activation-Deactivation Profile of Copper-Zinc Oxide Catalyst During Hydrogenation of Methyl Acetate
}

\author{
John Birtill ${ }^{1}$ D . Jon Deeley ${ }^{2} \cdot$ Craig Bailey $^{3}$
}

Accepted: 28 July 2021 / Published online: 18 August 2021

(c) The Author(s) 2021

\begin{abstract}
The deactivation of a copper-zinc oxide catalyst has been studied in a set of parallel tests which covered a range of spacetimes with equal flow and variable catalyst quantity, from $1 / 8$ th bed to full bed. The activation-deactivation trends over time in different segments of the full catalyst bed have been determined by two alternative parallel difference methods. The relative trends in segmental activity over time were followed by (a) using a pre-determined reaction model, and (b) by referencing the axial conversion profile against the initial profile. The trends estimated by both methods were in broad agreement. The results show that the front segment of the catalyst bed experienced a more rapid process of deactivation than the rest of the catalyst bed. This process is consistent with the known susceptibility of this type of catalyst to deactivation by chlorine and sulfur impurities in the feedstock. The main part of the catalyst bed appeared to undergo a process of activation during the first $150 \mathrm{~h}$, followed by a slow process of deactivation which was more rapid during periods at increased temperature. The slow deactivation is most likely associated with sintering of copper particles. The conversion parallel difference method provides a convenient and rapid tool for segmental analysis of parallel life tests, and is well-suited to resolving the impact of a poison front within a catalyst bed.
\end{abstract}

Keywords Catalyst deactivation $\cdot$ Parallel testing $\cdot$ Parallel difference $\cdot$ Copper-zinc oxide

\author{
Abbreviations \\ a Catalyst activity relative to fresh catalyst under the \\ same reaction conditions \\ $\mathrm{r}_{\mathrm{i}} \quad$ Forward rate of ith reaction \\ z Bed-fraction \\ $\mathrm{F}_{\mathrm{i}} \quad$ Flowrate of ith component in moles/h \\ Pe Axial Peclet Number \\ V Catalyst volume \\ W Catalyst mass \\ $\mathrm{X}$ Integral conversion \\ $\mathrm{X}_{\mathrm{m}} \quad$ Mean integral conversion in segment \\ $\tau$ Space-time W/F
}

John Birtill

John.Birtill@glasgow.ac.uk

1 Centre for Catalysis Research, School of Chemistry, University of Glasgow, Glasgow G12 8QQ, UK

2 BP International, Saltend, Hull HU12 8DS, UK

3 INEOS Acetyls UK, Hull HU12 8DS, UK

\section{Introduction}

Mike Spencer studied catalysis by copper during much of his long career at ICI (Imperial Chemical Industries) and Cardiff University, and published some notable papers on this topic. One such paper, co-written with long term collaborator, Martyn Twigg, reviewed the deactivation of supported copper metal catalysts for hydrogenation reactions [1]. This topic, appropriately, relates to the subject of this paper, which describes the evaluation of data generated in a set of tests, carried out from 2012 to 2014 in connection with a new process which was under development by BP International Limited.

Assessment of the stability of prospective catalyst formulations is a key task during development of any industrial catalytic process, and so catalyst deactivation is usually studied from an early stage of research. The dominant mechanism of catalyst deactivation of a fixed bed of catalyst can vary in different regions of the bed. The rate of any such process of deactivation can also vary with position in the bed, if temperature is variable, and/or if the rate is influenced by the local composition of the fluid phase [2]. Hence, integral 
reaction data are potentially misleading for studying catalyst deactivation in fixed beds. This problem can be overcome by carrying out multiple studies in differential or integral reactors, systematically covering a suitable range of space-time. However, progress in sequential deactivation experiments is usually too slow for industrial projects. Parallel testing in 8-tube fixed-bed micro-reactors was pioneered in ICI in the 1970s, using equipment designed in-house. The technique of 'parallel difference testing', using tests with equal flowrate and variable catalyst charges (i.e., variable space-time) to estimate change of the average activity over time in sequential segments of a fixed catalyst bed, has been described previously [3]. Methods for studying catalyst deactivation in fixed beds using available reactor types were reviewed for the Eurokin industrial-academic consortium in 2002-2004, and the suitability of parallel testing was highlighted [4]. The application of parallel difference testing to studying time-dependent activation phenomena has been described in several recent publications [5-7]. The work in this paper was described in outline at the Eurokin 20th anniversary symposium in 2018 [8]. The technology of parallel testing in micro-reactor units has been more widely adopted during the past 25 years, and test units with up to 64 parallel tubes are now commercially available.

The hydrogenation of methyl acetate to a mixture of methanol and ethanol was investigated in BP as part of a process for converting syngas to ethanol [9]. The hydrogenation is carried out in the vapour phase at high pressure over $\mathrm{Cu} / \mathrm{ZnO}$ hydrogenation catalyst. The main reactions are mildly exothermic [10]. The reactions are:

Methyl acetate $+2 \mathrm{H}_{2} \rightleftharpoons$ Ethanol + Methanol

$\Delta \mathrm{H}^{\circ}(\mathrm{g}, 298)=-29.00 \mathrm{~kJ} \mathrm{~mol}^{-1}$

Methyl acetate + Ethanol $\rightleftharpoons$ Ethyl acetate + Methanol

$\Delta \mathrm{H}^{\circ}(\mathrm{g}, 298)=-6.43 \mathrm{~kJ} \mathrm{~mol}^{-1}$

Ethyl acetate $+2 \mathrm{H}_{2} \rightleftharpoons 2$ Ethanol

$\Delta \mathrm{H}^{\circ}(\mathrm{g}, 298)=-22.57 \mathrm{~kJ} \mathrm{~mol}^{-1}$

The methanol co-product in reaction (1) is recycled in the process to the esterification unit for conversion to methyl acetate. Reaction (2) is the transesterification of the methyl acetate feed with the product ethanol. This reaction is facile and very fast compared with the hydrogenation reactions. Ethyl acetate is recycled within the hydrogenation unit to produce ethanol by reaction (3). This occurs over the same catalyst at similar rates to reaction (1). The hydrogenation
Table 1 Typical reaction conditions for hydrogenation of methyl acetate

\begin{tabular}{ll}
\hline Parameter & $\begin{array}{l}\text { Hydrogena- } \\
\text { tion condi- } \\
\text { tions }\end{array}$ \\
\hline Temperature & $200-300{ }^{\circ} \mathrm{C}$ \\
Pressure & $50 \mathrm{bar}$ \\
GHSV & $4000 \mathrm{~h}^{-1}$ \\
$\mathrm{H}_{2}:$ Ester ratio & $10: 1$ \\
\hline
\end{tabular}

reactions are almost complete at equilibrium under the reaction conditions. Typical conditions used are shown in Table 1.

The catalysts chosen for development were highly selective (>99\%) to ethanol. The transesterification reaction was not viewed as unselective as the ethyl acetate is recycled to produce ethanol. The main by-products of the chemistry are methane and ethane from exhaustive hydrogenation of the $\mathrm{C} 1$ and $\mathrm{C} 2$ alcohols and/or alkoxy fragments of the esters, and acetaldehyde, which is an intermediate in the hydrogenation of acetate esters to ethanol. Trace levels of $\mathrm{CO}$ and $\mathrm{CO}_{2}$ are also formed.

Known causes of deactivation of $\mathrm{Cu} / \mathrm{ZnO}$ catalysts include sulfur poisoning and thermal sintering which is accelerated by traces of chlorine via a surface migration mechanism [1]. Results from a previous 3-month microreactor test by BP were consistent with deactivation by poisoning, and this was supported by post-mortem analysis of the catalyst which found significant amounts of chlorine and sulfur. Subsequent work was carried out using much purer gas and liquid feedstocks. This reduced the chlorine and sulfur carried onto the catalyst in later tests, which indicated that deactivation was not caused exclusively by these poisons. Thermal sintering was a possible cause, but the deactivation rate did not seem unduly sensitive to increasing temperature in the range $200-260{ }^{\circ} \mathrm{C}$. Fouling was not expected to be a significant deactivation mechanism on account of the high partial pressure of hydrogen, and in practice no trace by-products with carbon chainlength $>\mathrm{C} 4$ were detected. The presence of traces of acetic acid from hydrolysis of the methyl acetate feedstock was another potential cause of deactivation, but in practice the level was very small.

The main objective of the work presented in this paper was to carry out a set of parallel difference tests at microreactor scale over several months to provide evidence that the target catalyst life in industrial use was realistic. A secondary objective was to provide mathematical insight for development of a predictive model of catalyst deactivation. The parallel difference tests were complementary to an additional life test at larger scale. 


\section{Methodology}

Ester conversion can be defined in two ways, based on inlet and outlet molar flow rates.

Acetate loss: $1-\left(\mathrm{F}_{\mathrm{MeOAc}}^{\mathrm{out}}+\mathrm{F}_{\mathrm{EtOAc}}^{\mathrm{out}}\right) /\left(\mathrm{F}_{\mathrm{MeOAc}}^{\mathrm{in}}+\mathrm{F}_{\mathrm{EtOAc}}^{\text {in }}\right)$

Ethyl product make: $\left(\mathrm{F}_{\mathrm{EtOH}}^{\text {out }}+\mathrm{F}_{\mathrm{EtOAc}}^{\text {out }}+\mathrm{F}_{\text {ethane }}^{\text {out }}\right) /$

$\left(\mathrm{F}_{\mathrm{MeOAc}}^{\text {out }}+2 * \mathrm{~F}_{\mathrm{EtOAc}}^{\text {out }}+\mathrm{F}_{\mathrm{EtOH}}^{\text {out }}+\mathrm{F}_{\text {ethane }}^{\text {out }}\right)$

Definition (ii) has been used throughout this work. The test plan was based on the parallel difference methodology mentioned above. The mean activity in each segment was determined from the experimental input and output data using a mechanistic kinetic model developed by BP using AthenaVisual Studio software from AthenaVisual Inc. The model incorporated the three main reactions and also the main by-product forming reactions described above. The data for the AthenaVisual model were measured over catalyst particles in a similar reactor unit to that used in this work. The model was fitted to a set of data collected after the catalyst had been operated for $1760 \mathrm{~h}$ over a range of conditions including temperatures in the range $210-260{ }^{\circ} \mathrm{C}$. The intrinsic activity of the catalyst $\left(\operatorname{molsg}_{\text {cat }}{ }^{-1} \mathrm{~h}^{-1}\right)$ is related to the abundance of active sites. The activity is expressed relative to the value 1.000 for fresh catalyst, which is assumed to be uniform throughout the catalyst bed, regardless of local composition of the fluid phase. The relative activity for any segment of catalyst is equivalent to the reaction rate $(\mathrm{mol} / \mathrm{h}$ converted per unit quantity of catalyst) compared to fresh catalyst under identical reaction conditions [2]. The activity in any location decays over time under local reaction conditions, but the reaction kinetics is assumed not to change. Hence, the model was used to calculate the mean activity for each catalyst charge at selected times from the reaction conditions and the integral conversion data.

An Excel version of the AthenaVisual model was used in this work. The catalyst bed in a reactor was divided into 200 step increments. The input data comprised quantity of catalyst for each reactor tube, feed rate for each component, and temperature and pressure which were the same for all tubes. In predictive mode the catalyst activity was pre-set, the change in the number of moles of each component was calculated during each step increment of catalyst nominal volume, and the final value of ester conversion was reported, based on definition (i) and/or (ii) above.

In order to determine the mean activity for the quantity of catalyst in each reactor, the model was used in iterative mode. The progression of the reaction over the step increments in catalyst volume was calculated by the same procedure as above during each iteration. The mean catalyst activity for each catalyst charge at any time was calculated from the collected data by a goal-seeking macro, which adjusted the mean activity so that the overall conversion calculated by the model agreed with the observed value, based on definition (ii). The progress of catalyst deactivation was followed by determining mean activity of segments of the catalyst bed at pre-set reference conditions for feed composition, feed rate, temperature and pressure, and so the model was only required to adjust the activity to match the integral reaction data at these pre-set conditions.

The catalyst charge in individual tubes in this work was approximately $12.5 \%, 25 \%, 50 \%, 75 \%$ and $100 \%$ of a full charge. This enabled the catalyst bed to be divided into 5 segments, corresponding to $\mathrm{z}=0-0.125,0.125-0.25$, $0.25-0.5,0.5-0.75,0.75-1.0$. The mean activity of the smallest front segment was determined directly. The mean activity in subsequent segments was calculated by a simple weighted difference calculation between neighbouring segments.

$\mathrm{a}_{0.125-0.25}=\left(0.25 * \mathrm{a}_{0.25}-0.125 * \mathrm{a}_{0.125}\right) /(0.25-0.125)$

An alternative method which does not require a predetermined reaction model has been described by Corella et al. [11] A series of life tests was carried out in an integral reactor at different values of space-time (W/F or $\tau$ ) with fixed linear gas velocity, and so presumably varying catalyst quantity $[4,11]$. At any fixed reaction time, the gradient at any value of space-time in a plot of integral conversion against space-time provided a measure of the reaction rate at that space-time. Comparison with the gradient at the same conversion value for the equivalent plot with fresh catalyst $(t=0)$ allowed direct determination of the point activity for any value of space-time at any reaction time.

The conversion profiles can alternatively be referred to catalyst volume as in Figs. 10 and 11, or axial bed-fraction $\mathrm{z}$ rather than space-time.

Corella's work was apparently based on manual curve-fitting and gradient determination. The method can be adapted by fitting polynomial expressions to the $\mathrm{X}-\tau$ plots at fixed reaction times. The derivative at any selected space-time is compared to the derivative for fresh catalyst at the same conversion value, obtained from a plot of $d X / d \tau$ against $X$ for fresh catalyst. The plot of $d X / d \tau$ against $X$ at $t=0$ is a simple empirical reaction model which is valid only for the reaction conditions during the experiment.

$a=\frac{\left(\frac{d X}{d \tau}\right)_{\tau, X, t}}{\left(\frac{d X}{d \tau}\right)_{X, t=0}}=\frac{\left(\frac{d X}{d V}\right)_{V, X, t}}{\left(\frac{d X}{d V}\right)_{X, t=0}}=\frac{\left(\frac{d X}{d z}\right)_{z, X, t}}{\left(\frac{d X}{d z}\right)_{X, t=0}}$

Note that this method generates point activity values rather than the mean segmental activity values determined in the parallel difference method. Corella's method had 
already been tried on another project, but in practice the variation of the point activity values with time was found to be rather noisy, a consequence of data scatter and multiple polynomial fits.

\section{Experimental}

A commercial $\mathrm{CuO} / \mathrm{ZnO}$ catalyst was used in this work. Catalyst pellets were broken and sieved to particle size range $350-500 \mu \mathrm{m}$.

The tests were carried out at hteGmbh in a high throughput (HT) unit with 16 parallel reactors, vertically mounted in a heated block with all catalyst beds located in the isothermal zone. The HT test plate comprised an inert-packed tube for feed analysis and seven catalyst tubes with five values of catalyst charge, two of them duplicated, i.e., approximately $12.5 \%, 25 \% \times 2,50 \%, 75 \%$ and $100 \% \times 2$ of a full charge $(1.696 \mathrm{~g}, 1.06 \mathrm{ml})$. The charge quantity was measured by mass, and all calculations of intrinsic activity $\left(\right.$ molsg $\left._{\text {cat }}{ }^{-1} \mathrm{~h}^{-1}\right)$ referred to catalyst mass. However, the nominal catalyst volume has also been used in this work to refer to bed position. An internal tube diameter of $4.5 \mathrm{~mm}$ was selected in order to accommodate the full bed in the isothermal zone. The same tube diameter was used for the $75 \%$ and $50 \%$ beds. It was intended in the original test plan that all reactors should have the same diameter, but a smaller tube diameter of $3.6 \mathrm{~mm}$ was used in practice for the three smallest beds $(12.5 \%$, and $25 \% \times 2)$. The generally accepted criteria for tubular catalyst beds, derived by Mears and others, aim to limit deviations from plug flow or isothermality [12-15]. The reactor dimensions and particle size range used in this work comfortably satisfied the criterion for limiting axial dispersion $\left(\mathrm{L}_{\mathrm{R}} / \mathrm{d}_{\mathrm{P}}>20 \mathrm{n} * \ln (1 / 1-\mathrm{X}) / \mathrm{Pe}\right)$, and complied reasonably well with the criterion $d_{R} / d_{P}>10$ for limiting wall bypassing. The actual ratio $\mathrm{d}_{\mathrm{R}} / \mathrm{d}_{\mathrm{Pmean}}$ for the $3.6 \mathrm{~mm}$ tubes was slightly low at 8.5 , but the range of particle sizes should allow slightly better packing. The criterion for limiting the impact of the radial temperature gradient on observed rate is more complex, involving the activation energy, the heat output intensity $(\mathrm{kJ} / \mathrm{s} / \mathrm{ml})$, and heat transfer across the bed and tube wall. The reactions in this study are mildly exothermic. The criterion was found to be satisfied for either tube diameter in the region of greatest reaction rate at the reference temperature, using approximate estimates for heat transfer parameters. The radial $\Delta \mathrm{T}$ was estimated to be $<0.1{ }^{\circ} \mathrm{C}$ for either tube diameter. The criterion aims to limit the systematic deviation of measured reaction rate to $<5 \%$, whereas the present study concerns the change of activity over time relative to fresh catalyst. The internal referencing of mean segmental activity against fresh catalyst would tend to compensate for any small error introduced to the difference calculations due to the step change in tube diameter, especially using method (b) described later.

The catalysts were pre-reduced before the start of the reaction using an established procedure [9]. This involved heating to $100{ }^{\circ} \mathrm{C}$ under $5 \% \mathrm{H}_{2}$ in $\mathrm{N}_{2}$ at $2.5 \mathrm{MPa}$, GHSV $6000 \mathrm{~h}^{-1}$. The concentration of $\mathrm{H}_{2}$ was then increased in stages to $10 \%, 20 \%, 40 \%, 70 \%$ and $100 \%$ with a $1 \mathrm{~h}$ dwell time at each stage. The catalyst was heated at $1{ }^{\circ} \mathrm{C} / \mathrm{min}$ to a holding temperature of $180^{\circ} \mathrm{C}$, and was held for a dwell time of $24 \mathrm{~h}$. At this point, catalyst activation was considered complete.

The main feed components were hydrogen $(88.1 \%)$ and methyl acetate $(8.81 \%)$, at the target $10 / 1$ hydrogen/ ester molar ratio. The minor components were methanol $(2.35 \mathrm{~mol} \%)$, nitrogen $(0.12 \%)$ and water $(0.6 \%)$. In practice, as explained below, the hydrogen/ester ratio was initially lower than target (8.5/1-9/1) until it was re-set after $753 \mathrm{~h}$. The presence of water in the feed was necessary to ensure that its promotional effect on the reaction kinetics was constant and not affected by the generation of a small amount of water by the reverse water gas shift reaction [9]. A small quantity of heptane was used as an internal standard.

The liquid feed mixture (ester/methanol/water) was metered by HPLC pump directly without any guard bed. Liquid feedstocks with very low sulfur and chlorine content were used in order to minimise poisoning. The hydrogen feed was controlled by a mass flow meter and passed through a sulfur guard bed.

The test design required flow rate to be equal through all tubes at all times, thereby enabling deactivation to be estimated in different segments of a full bed. The pressure drop across two capillary tubes, mounted upstream and downstream of each reactor, was significantly greater than the pressure drop across individual reactors. Hence, the flow rate through all reactors was equal by design, regardless of the quantity of catalyst.

The total feed rate through all reactor tubes was calculated from the combined values of the inlet mass-flow controller and HPLC pump.

Analysis by GC was carried out for organic components using a Plot Q column with FID, and for water using a Volamin column with TCD. $\mathrm{CO}$ and $\mathrm{CO}_{2}$ were detected by IR-based online process analysers. The analyses were carried out cyclically over all 7 catalyst tubes with corresponding feed analyses. The timescale of the analytical cycle was small compared to the overall timescale of the test, and deactivation was very slow. It was therefore valid to use the mean value of time on stream for each analytical cycle. This was convenient for interpretation of data. The measurements of feed composition and feed rate were also averaged within each analytical cycle as this gave better precision and consistency for carbon balance over all tests, compared to 

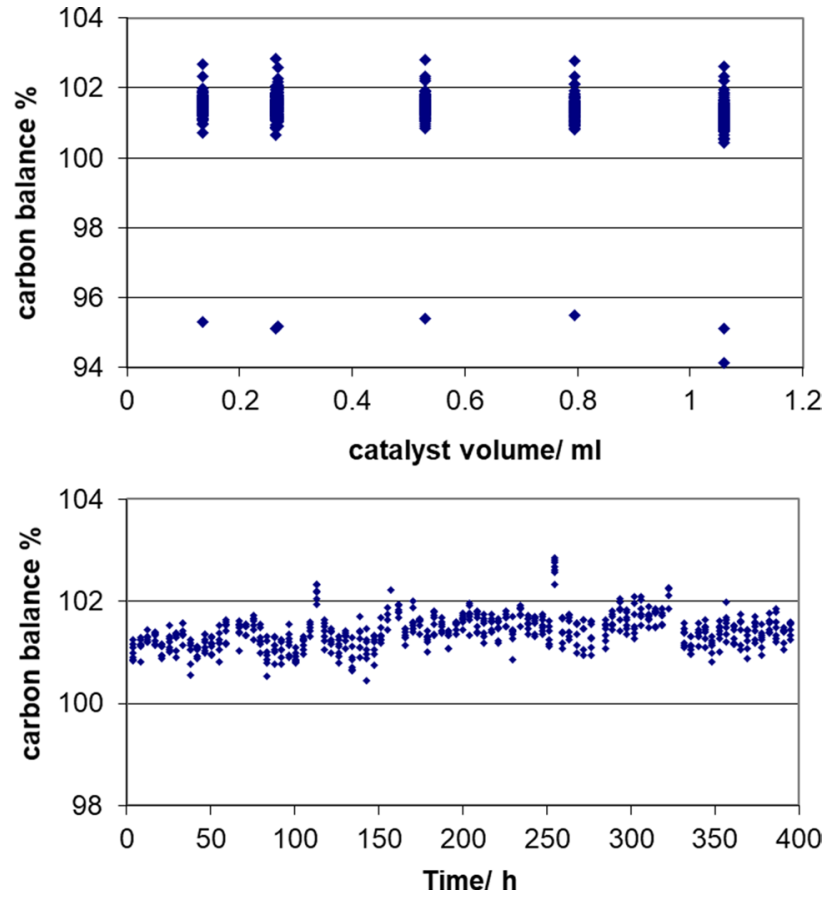

Fig. 1 Carbon balance for all tests during initial test period 0-395 h. Carbon balance $=100 *($ total moles carbon in product stream $) /($ total moles carbon in feed). Data at $\mathrm{t}=0$ in upper plot with value $\sim 95 \%$ excluded from study and so not shown in lower plot against time

seven separate measurements per cycle. The carbon balance is shown in Fig. 1. The values were poor in the first analytical cycle at $\mathrm{t} \sim 0$, and the conversion values were also inconsistent with subsequent values recorded at $t=4 \mathrm{~h}$. It was concluded that the tests had not settled well during the first cycle. The initial set of data was therefore disregarded, and deactivation was studied relative to the activity at $\mathrm{t}=4 \mathrm{~h}$. The carbon balance during the first $400 \mathrm{~h}$ was in the range $101-102 \%$ for all tests, and there was no systematic variation with conversion, suggesting a small mismatch between inlet and outlet flowrate. Definition (ii) for conversion is independent of inlet flowrate, and so was therefore preferred.

There was a leak of hydrogen during the initial period of the test (0-753 h), and the $\mathrm{H}_{2}$ /ester ratio was lower than the 10/1 target during this time. It was then corrected to the target value. The ratio of other feed components to methyl acetate was constant throughout. There was also a trip and shutdown at $975 \mathrm{~h}$ due to a failure of the control system. The catalyst was held cold under nitrogen for 2 weeks and then restarted. The cold shutdown period was excluded from the recorded time on stream. The final conditions are shown below in Table 2.

The GHSV was increased during periods at higher temperature in order to constrain the conversion in the full bed. The conditions were returned to the reference (starting) conditions after each period at higher temperature so that
Table 2 Test conditions for full bed

\begin{tabular}{lllll}
\hline Period & Temp $\left({ }^{\circ} \mathrm{C}\right)$ & GHSV $\left(\mathrm{h}^{-1}\right)$ & H2/Ester ratio & Duration $(\mathrm{h})$ \\
\hline 1 & 210 & 3900 & 8.5 & $0-396$ \\
2 & 220 & 6000 & 9.2 & $400-700$ \\
$3 \mathrm{a}$ & 210 & 4000 & 8.5 & $704-753$ \\
$3 \mathrm{~b}$ & 210 & 4520 & 10 & $833-900$ \\
4 & 240 & 12,060 & 10 & $900-970$ \\
5 & 210 & 4500 & 10 & $976-1012$ \\
6 & 240 & 12,000 & 10 & $1017-1254$ \\
7 & 210 & 4500 & 10 & $1260-1275$ \\
8 & 260 & 15,500 & 10 & $1280-1684$ \\
9 & 210 & 4500 & 10 & $1694-1711$ \\
\hline
\end{tabular}

Other feed components at fixed ratio to ester feed. Pressure $=51$ bar (a)

the degree of deactivation could be estimated with minimal dependence on the parameters of the reaction kinetic model. It was recognised that the step change in composition at $753 \mathrm{~h}$ might affect interpretation of the deactivation trend after this time.

\section{Results and Interpretation}

The product distribution in this reaction consists mainly of ethanol and ethyl acetate with only trace levels of $\mathrm{CH}_{4}, \mathrm{C}_{2} \mathrm{H}_{6}$, $\mathrm{CO}, \mathrm{CO}_{2}$ and $\mathrm{H}_{2} \mathrm{O}$. Acetic acid was negligible throughout. Selectivity to ethanol was $>99 \%$. Conversion $\mathrm{X}$ was based on product analysis using definition (ii). The transesterification reaction (2) is relatively fast. Figure 2 shows that the ratio of the main products for any specified ester conversion at $210{ }^{\circ} \mathrm{C}$ was constant, regardless of catalyst age and catalyst quantity, consistent with attainment of equilibrium.

Thermodynamic equilibrium for the ester hydrogenation reaction is achieved under these conditions at $\sim 97 \%$ ester conversion according to the reaction model. The estimated

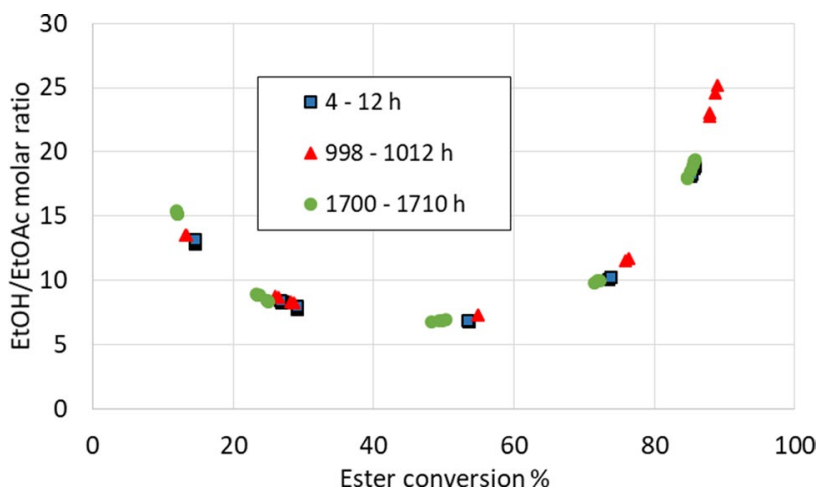

Fig. 2 Constant product ratio for specified ester conversion at $210{ }^{\circ} \mathrm{C}$ 


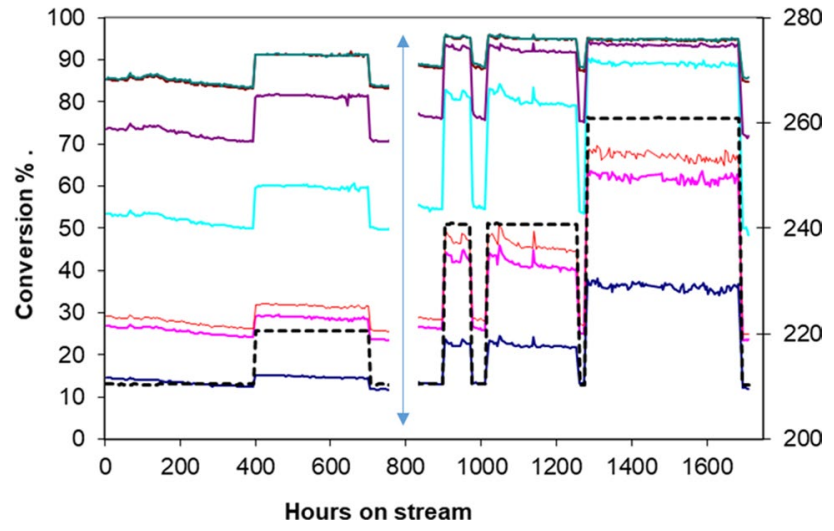

Fig. 3 Conversion trends for all reactors. Dashed line: average reactor temperature. Vertical double-arrow: step-change in H2/ester ratio at $753 \mathrm{~h}$. No data recorded during period 753-835 h. Data excluded for 2 weeks of cold shutdown after trip at $975 \mathrm{~h}$

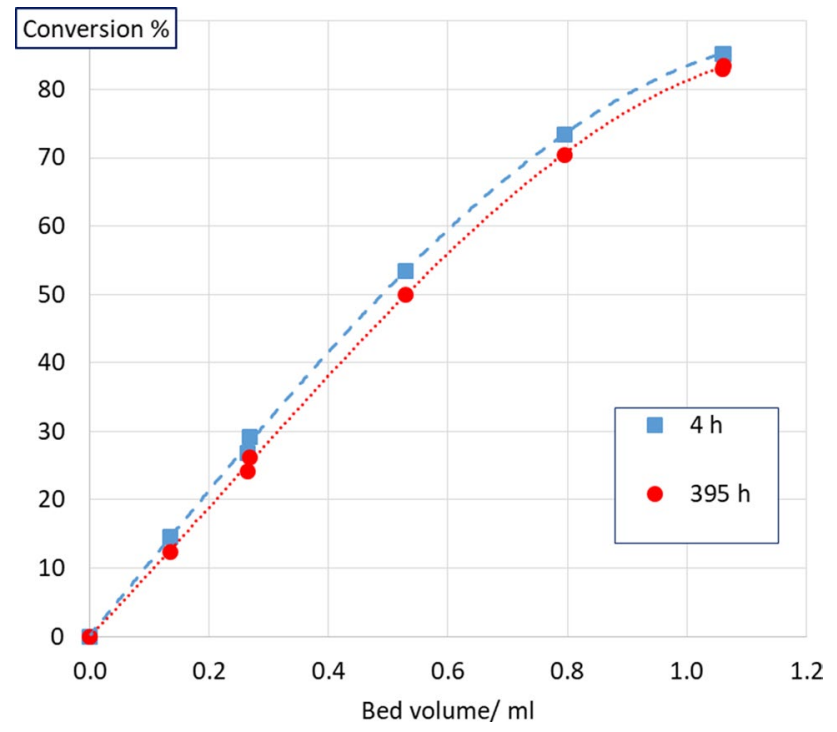

Fig. 4 Conversion profiles for all beds at selected times

catalyst activity was observed in previous work to become progressively less precise during the approach to equilibrium, and so, for reliable measurements of activity, conversion was limited to $85 \%$ during the first $400 \mathrm{~h}$ of testing. The limit was exceeded in the longer beds during later periods at high temperature or at increased $\mathrm{H}_{2} /$ ester ratio after $753 \mathrm{~h}$.

The conversion trends for all reactors for the duration of the test are shown in Fig. 3.

The conversion data for the first $400 \mathrm{~h}$ are shown in Figs. 4 and 5. The flat conversion-time profiles for the half to full beds in Fig. 5 could give the impression that the catalyst was stable for the first $150 \mathrm{~h}$, after which time it started to deactivate slowly. However, the shortest bed showed deactivation from much earlier in the experiment. Close inspection of the raw conversion data for all beds shows that conversion decreased in the smaller (1/8 to $1 / 2)$ beds during the first $140 \mathrm{~h}$, but increased in the $3 / 4$ and full beds. The magnitude of the conversion change was systematic with bed length, indicating a genuine activation process rather than random error.

Occasional small simultaneous discontinuities in ester conversion were observed in all tubes with no obvious cause, such as the short-lived event at $67-75 \mathrm{~h}$ in Fig. 5. All feeds, temperatures and pressure were stable at this time, and so the cause, whether experimental or instrumental, was unknown. Hence, all data points were retained. The estimated conversion was found to be significantly more variable during and after some later test periods at high temperature, especially so at high conversion. Some data measured at $210^{\circ} \mathrm{C}$ after $1000 \mathrm{~h}$ were averaged over short periods of time in order to improve precision.

In order to estimate the relative deactivation of segments of the catalyst bed over time, the initial axial activity profile determined from the reaction model must be uniform for the conditions of the experiment, i.e., same initial value of 1.000 for relative activity of all charges of catalyst, and hence for all segments. The initial activity for each charge was set relative to the initial mean value for all seven tests at $\mathrm{t}=4-8 \mathrm{~h}$. Values were close to 1.000 in practice, but the initial activity was relatively high for the shortest bed, and the mean activity showed a pronounced downward slope with conversion and bed fraction. The model parameters had been fitted previously to catalyst performance data measured on aged catalyst which had already deactivated to some extent. Chlorine and sulfur are known to deactivate this type of catalyst from the front of the catalyst bed in other applications, and a poison profile down the bed had previously been observed in this system. This would cause the model parameters to be distorted to compensate for front-end deactivation, and the activity for a short bed of fresh catalyst at low conversion to be overestimated. The sensitivity of the activity profile to selected model parameters was therefore examined. The activity profile was found be insensitive to the rate constants for the main reactions $r_{1}-r_{3}$, but it was sensitive to the order $\mathrm{n}$ for the concentration of free active sites, as shown in Fig. 6. The order $n$ was adjusted by trial and error for the analytical cycles at 4 and $8 \mathrm{~h}$. A near uniform activity profile against charge volume was achieved with $n=1.87$.

The plot of values over the first $400 \mathrm{~h}$ is shown in Fig. 7. The initial values of the five catalyst charges were all close to 1.000 but still with some scatter as in Fig. 6. Four of the five catalyst charges showed similar deactivation trends over time, and the initial scatter in mean activity values was retained. However, the smallest charge clearly deactivated faster than the others.

It was necessary to remove the initial scatter in the activity values in order to calculate segmental activity by difference. This was achieved by normalizing the activity in 
Fig. 5 Conversion trends for all beds over first $400 \mathrm{~h}$. Line fits shown for initial activation period $0-140 \mathrm{~h}$ for all beds. Removal of data at $67-75 \mathrm{~h}$ improved $\mathrm{R}^{2}$ values for all plots without changing gradients. Additional line fit shown for the shortest bed for $140-395 \mathrm{~h}$

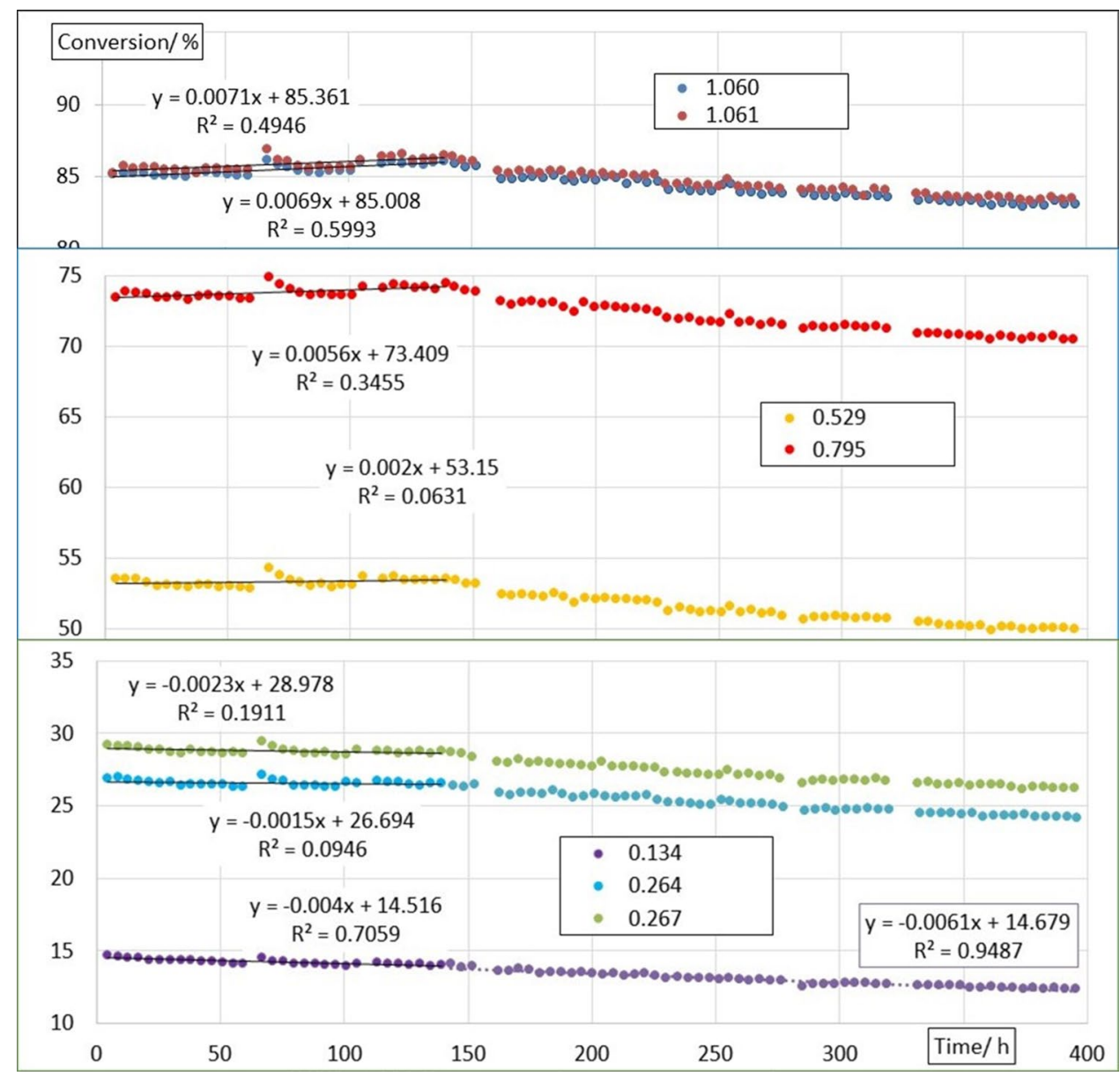

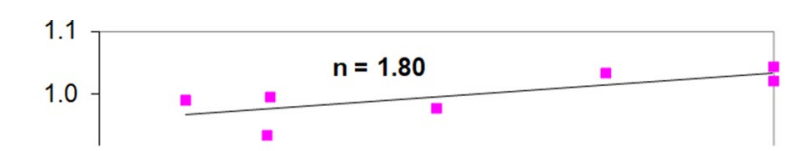

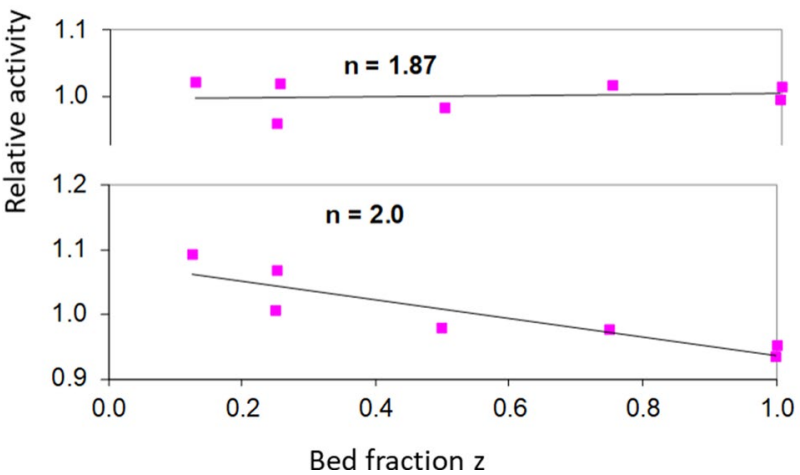

Fig. 6 Effect of site-order $\mathrm{n}$ on relative activity profile for fresh catalyst. The activity is the mean value for the entire charge in each test relative to the mean value for all seven tests at $t=4 \mathrm{~h}$. The relative values for the duplicated tests $(z=0.25$ and 1.0$)$ were averaged in the main analysis

each test against its own initial value. The equivalent plot of values for all seven tests is shown in Fig. 8. The initial

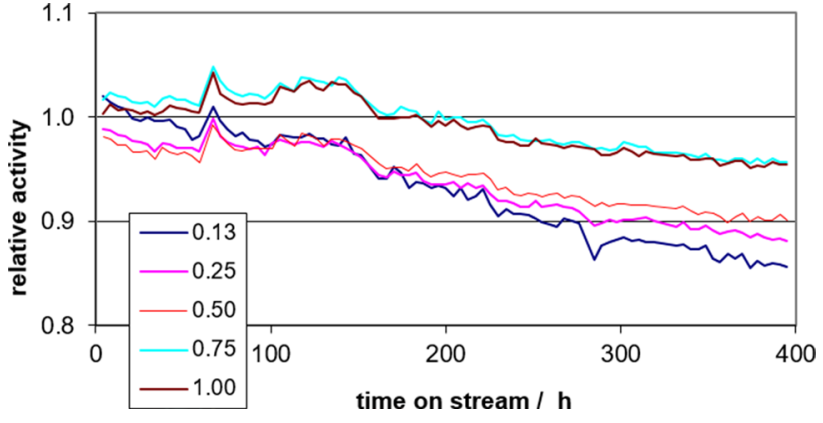

Fig. 7 Variation of mean activity over time $0-400 \mathrm{~h}$. The activity is the mean value for the entire charge in each test or pair of tests relative to the mean value for all seven tests at $\mathrm{t}=4 \mathrm{~h}$

activity for each test was now by definition equal to 1.000 . As noted already, the smallest catalyst charge $(z=0.125)$ deactivated faster than the other six charges. The two pairs of duplicated tests $(\mathrm{z}=0.25$ and 1.0$)$ followed very similar trends. This boosted confidence in the validity of the strategy. The data for these two pairs at subsequent times were averaged before determination of segmental activity by difference calculations. 


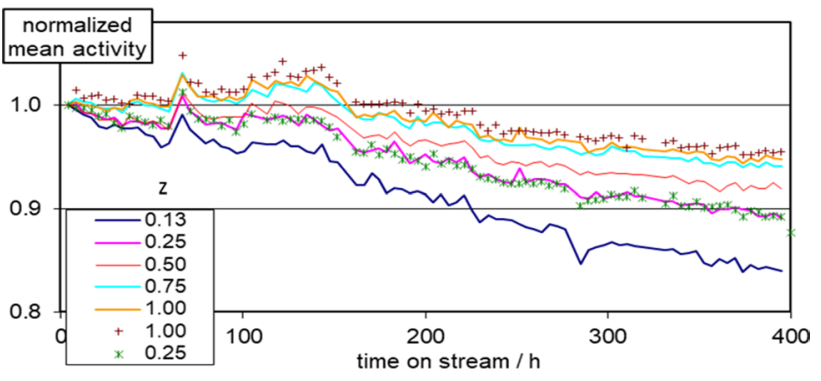

Fig. 8 Normalized mean activity data for each reactor charge. The value for each reactor charge is normalized against its initial value at $\mathrm{t}=4-8 \mathrm{~h}$

The mean segmental activity values were determined by difference using Eq. (iii). The segmental trends for the first period at $210{ }^{\circ} \mathrm{C}$ are shown in Fig. 9. It has already been noted from the plot of conversion in Fig. 5 that the deactivation rate was fast in the shortest $1 / 8^{\text {th }}$ bed which is equivalent to the front segment $(0-0.125)$ of all the other beds. The other segments of the full bed showed a broadly similar initial period of activation over $0-150 \mathrm{~h}$, followed by progressive deactivation at a slower rate than the front segment. The two segments in the rear half of the bed $(z=0.5-0.75$ and $0.75-1.0)$ appeared to activate a little more than the $0.125-0.25$ and $0.25-0.5$ segments in the front half of the bed. This could be a genuine effect, but inspection of the non-averaged difference data for the duplicated full bed suggested that the sensitivity of difference calculations to experimental error might be a contributing factor. The deactivation rate in the front $0-0.125$ segment increased after $150 \mathrm{~h}$, suggesting that the catalyst in this segment had also experienced the activation process as well as a localized deactivation process.

The apparent segmental activation from 0 to $150 \mathrm{~h}$ was not caused by the difference method, and as noted already, was evident in the conversion trends for all beds in Fig. 5 . The magnitude of the conversion change was systematic

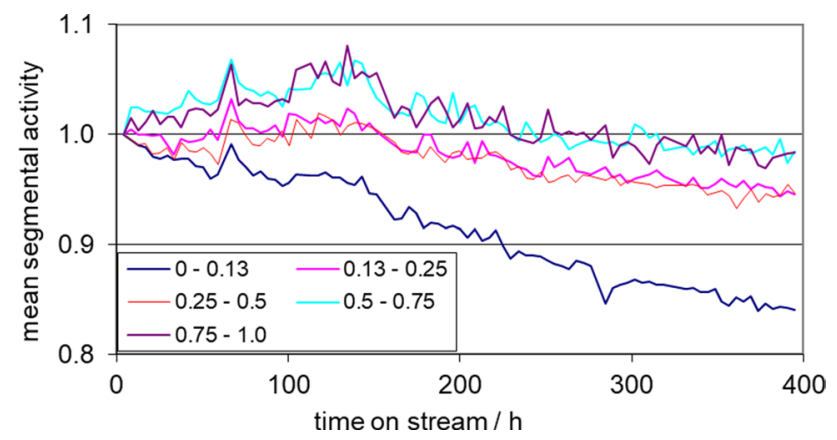

Fig. 9 Segmental activity-time trends over $0-400 \mathrm{~h}$ on stream with bed length, and so was not due to random error. The most likely cause was a genuine activation process.

The overall observations illustrate the key requirements for the parallel difference method, namely stable reaction conditions, precise and accurate data, preferably duplicate or triplicate parallel tests, and a reaction model that gives a uniform activity profile at start of life.

If the reaction model is not available, then it is necessary to derive the segmental activity time trends by other means. The determination of point activity values by the method of Corella, described earlier, had already been found in another project to give rather noisy deactivation-time plots. The method was tried again with this set of data. The variation of conversion with volume of fresh catalyst is shown in Fig. 10.

The $\mathrm{X}-\mathrm{V}$ data were fitted to trial polynomial equations, constrained to pass through the origin. The fourth order polynomial fit was selected. The fit using average data for both analytical blocks at $4 \mathrm{~h}$ and $8 \mathrm{~h}$ was no better than using the data only at $4 \mathrm{~h}$ and so the data at $4 \mathrm{~h}$ were taken to be representative of fresh catalyst.

The curve-fitting covered the initial data for all seven catalyst charges, and so there was no need for any corrective normalization to compensate for the natural scatter in activity for individual charges.

The polynomial equation was differentiated to determine the dependence of the gradient $\mathrm{dX} / \mathrm{dV}$ with conversion, as plotted in Fig. 11 which is effectively a simple reaction model for fresh catalyst, showing how the reaction rate per unit volume of catalyst varied with conversion under the prevailing conditions. $\mathrm{dX} / \mathrm{dV}$ must equal zero at equilibrium, defining the maximum conversion. $\mathrm{X}_{\max }$ was initially set at 90\% from inspection of the data, but is set at $97 \%$ in Fig. 11 for comparison with output from the reaction model, which predicts equilibrium conversion at this value. The plot of $\mathrm{dX} /$ $\mathrm{dV}$ against $\mathrm{X}$ was then also fitted to a 4 th order polynomial. The corresponding plots with $X_{\max }$ set at $90 \%$ and $92 \%$ gave only slightly less good fits.

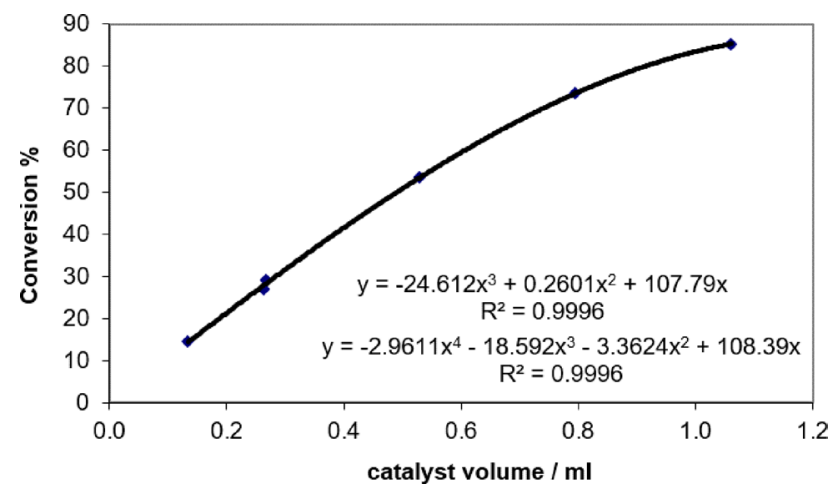

Fig. 10 Variation of conversion $\mathrm{X}$ with catalyst bed volume for fresh catalyst at $\mathrm{t} \sim 4 \mathrm{~h}$ 


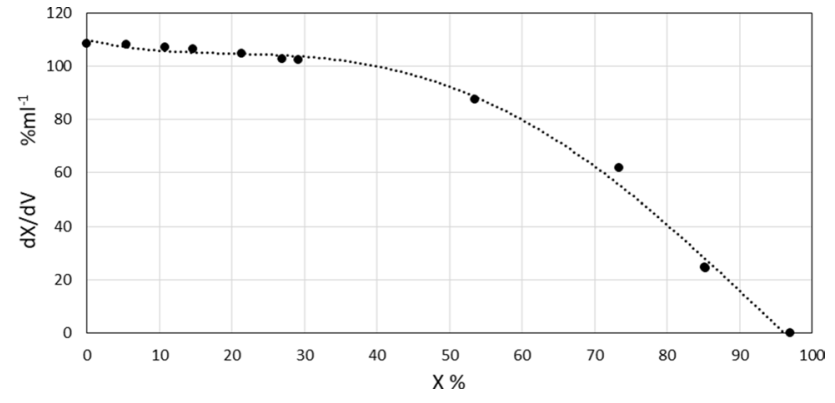

Fig. 11 Variation of $\mathrm{dX} / \mathrm{dV}$ for fresh catalyst at $\mathrm{t} \sim 4 \mathrm{~h}$. Plot based on fourth order polynomial fit to Fig. 10. Constraint: $d V / d X=0$ at $\mathrm{X} \max =97.0 \%$

The initial calculations were made of point activity at selected times, based on Corella's method. See Eq. (iv). Equivalent $\mathrm{X}-\mathrm{V}$ plots to Fig. 10 were generated for each time-block of data, and the $\mathrm{dX} / \mathrm{dV}$ values at each bed position were normalised with respect to $\mathrm{dX} / \mathrm{dV}$ at the same $\mathrm{X}$ for fresh catalyst from the polynomial fit to Fig. 11. However, the $\mathrm{X}-\mathrm{V}$ curve fitting procedure for each time-block was laborious, and the $\mathrm{dX} / \mathrm{dV}$ values were rather imprecise at the highest conversion as the curvature of the $\mathrm{X}-\mathrm{V}$ plot needed to be extrapolated beyond the highest observed value of conversion.

The determination of mean segmental activity $\mathrm{a}_{\mathrm{m}}$ by parallel difference using Eq. (iii) had several advantages over the determination of point activity. Firstly, the values for each segment at each time could be carried out by simple conversion difference calculations for each time-block of data rather than multiple curve-fitting operations. Secondly, the difference calculation was more precise than the differential calculation at high conversion as it did not rely on any extrapolated curvature. Thirdly, the resulting values of mean segmental activity were in principle equivalent to the mean segmental activity values calculated using the reaction model.

The values for mean segmental activity over $0-400 \mathrm{~h}$ were determined from the data at $210^{\circ} \mathrm{C}$, using average data for duplicate beds. Two methods were tried, as reported previously [8].

$a_{\Delta z}=\frac{\left(\frac{\Delta X}{\Delta V}\right)_{\Delta z, t}}{\left(\frac{d X}{d V}\right)_{X m, t=0}}$

$a_{\Delta z}=\frac{\left(\frac{\Delta X}{\Delta V}\right)_{\Delta z, t}}{\left(\frac{\Delta X}{\Delta V}\right)_{\Delta X, t=0}}=\frac{\left(V_{c a l c}^{X 2, t=0}-V_{c a l c}^{X 1, t=0}\right)}{\left(V_{o b s}^{X 2, t}-V_{o b s}^{X 1, t}\right)}$

(a) $\Delta \mathrm{X} / \Delta \mathrm{V}(\mathrm{t})$ and mean conversion values $\mathrm{X}_{\mathrm{m}}$ were determined for each segment $\Delta \mathrm{z}$, and each $\Delta \mathrm{X} / \Delta \mathrm{V}(\mathrm{t})$ value was divided by the point differential value $\mathrm{dX} / \mathrm{dV}$ at $\mathrm{X}_{\mathrm{m}}$ for fresh catalyst from Fig. 11, as per Eq. (v). This gave $\mathrm{a}_{0}$ values which were close to 1.000 , but slightly offset for each segment, and so additional normalisation was required to achieve $\mathrm{a}_{0}=1.000$ for all segments. The values were also sensitive to extrapolation of the $\mathrm{X}-\mathrm{V}$ plot to the equilibrium value $\mathrm{X}_{\max }$, causing some deviation to the activity-time trend for the end segment $\mathrm{z}=0.75-1.0$.

(b) A polynomial expression was fitted in Fig. 12 to match almost exactly the $\mathrm{V}-\mathrm{X}$ plot for fresh catalyst at $\mathrm{t}=4 \mathrm{~h}$. This plot was then used to determine the volume of fresh catalyst required to achieve the conversion values observed at later times. The $\Delta \mathrm{X} / \Delta \mathrm{V}(\mathrm{t})$ value for each segment was divided by $\Delta \mathrm{X} / \Delta \mathrm{V}$ for exactly the same range of $\mathrm{X}$ at $\mathrm{t}=0$, the calculation reducing to the simple volume ratio as per Eq. (vi).

Method (b) was preferred in this study as it was easy to evaluate, the $\mathrm{V}-\mathrm{X}$ plot was independent of the exact value of equilibrium $\mathrm{X}_{\max }$, and the good initial fit gave by definition values for initial activity close to 1.000 for all segments.

The initial results using this method for the first period from 0 to $400 \mathrm{~h}$ at $210{ }^{\circ} \mathrm{C}$ are shown in Fig. 13. The correspondence with the deactivation trends evaluated using the model, shown in Fig. 9, is not perfect but it is reasonably

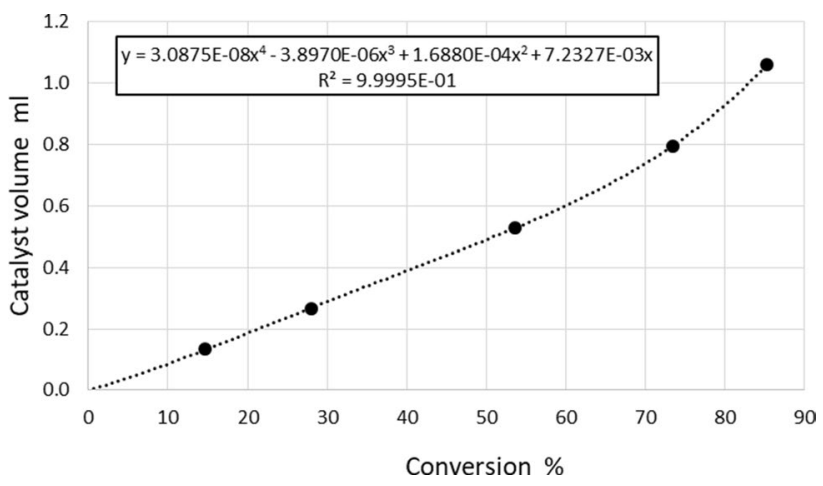

Fig. 12 Relation between catalyst volume and conversion for fresh catalyst at $\mathrm{t} \sim 4 \mathrm{~h}$. mean values for $\mathrm{X}$ and $\mathrm{V}$ from duplicate tests

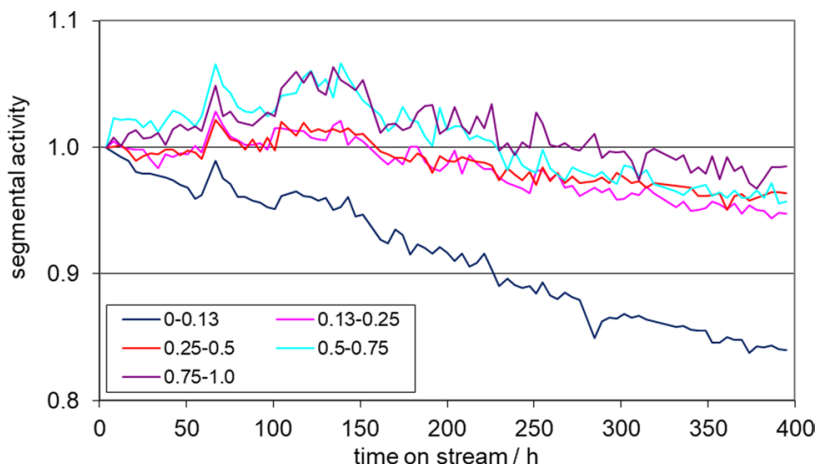

Fig. 13 Mean segmental activity values calculated by parallel difference matched $\Delta \mathrm{X} / \Delta \mathrm{V}$ Eq. (vi) 
good. The relative trends for the three mid-bed segments are just slightly displaced between the two plots.

The segmental trends over the whole test, shown in Fig. 14a-c, suggest that some additional activation may have occurred at $220{ }^{\circ} \mathrm{C}$ during the period $400-750 \mathrm{~h}$.

The original intention was to monitor deactivation trends by returning to the initial reaction conditions as a reference baseline. However, as explained earlier, the $\mathrm{H}_{2}$ /ester ratio had initially been set lower than intended for the life test. The $\mathrm{H}_{2}$ /ester ratio was corrected to the original target value after $753 \mathrm{~h}$, as recorded in Table 2. This meant that comparison of initial reference measurements at $210^{\circ} \mathrm{C}$ with later reference measurements at $210^{\circ} \mathrm{C}$ was affected by the step change in $\mathrm{H}_{2}$ /ester ratio. The reaction model was not sufficiently exact to compensate for the step change, and so the calculated segmental activity values in Fig. 14a showed another discontinuity after $753 \mathrm{~h}$. The reaction model was, as expected, also not sufficiently exact to adjust activity values measured at high severity to reference conditions, and so periods at high temperature have been excluded from the plot.

The segmental deactivation trends diverged somewhat after $900 \mathrm{~h}$ and $1000 \mathrm{~h}$ following periods at $240{ }^{\circ} \mathrm{C}$. The top $0-0.125$ segment became a little more active, whereas the $0.125-0.25$ segment decayed faster than the $0.25-0.5$ segment between 1000 and $1300 \mathrm{~h}$, possibly indicating some migration of poison down the bed from the front-end. All segments had decayed significantly by $1730 \mathrm{~h}$ following a period at $260{ }^{\circ} \mathrm{C}$.

The step change in $\mathrm{H}_{2}$ /ester ratio might also affect the deactivation rate to some extent but any such effect was obscured within the overall trends.
Fig. 14 Segmental deactivation trends at $210{ }^{\circ} \mathrm{C}$ determined by parallel difference using a reaction model $\mathbf{b} \mathrm{V}-\mathrm{X}$ profile c $\mathrm{V}-\mathrm{X}$ profile corrected for step-change in $\mathrm{H}_{2}$ /ester ratio. Catalyst operated at higher temperature during periods shown in top graph. See Table 2 for more details. Further activation during period at $220{ }^{\circ} \mathrm{C}$ from 400 to $700 \mathrm{~h}$. Vertical dashed line denotes change of $\mathrm{H}_{2}$ /ester ratio after $753 \mathrm{~h}$. Average data points from 3 or 4 readings after $\sim 1000 \mathrm{~h}$. Cold shutdown after trip at $975 \mathrm{~h}$ excluded
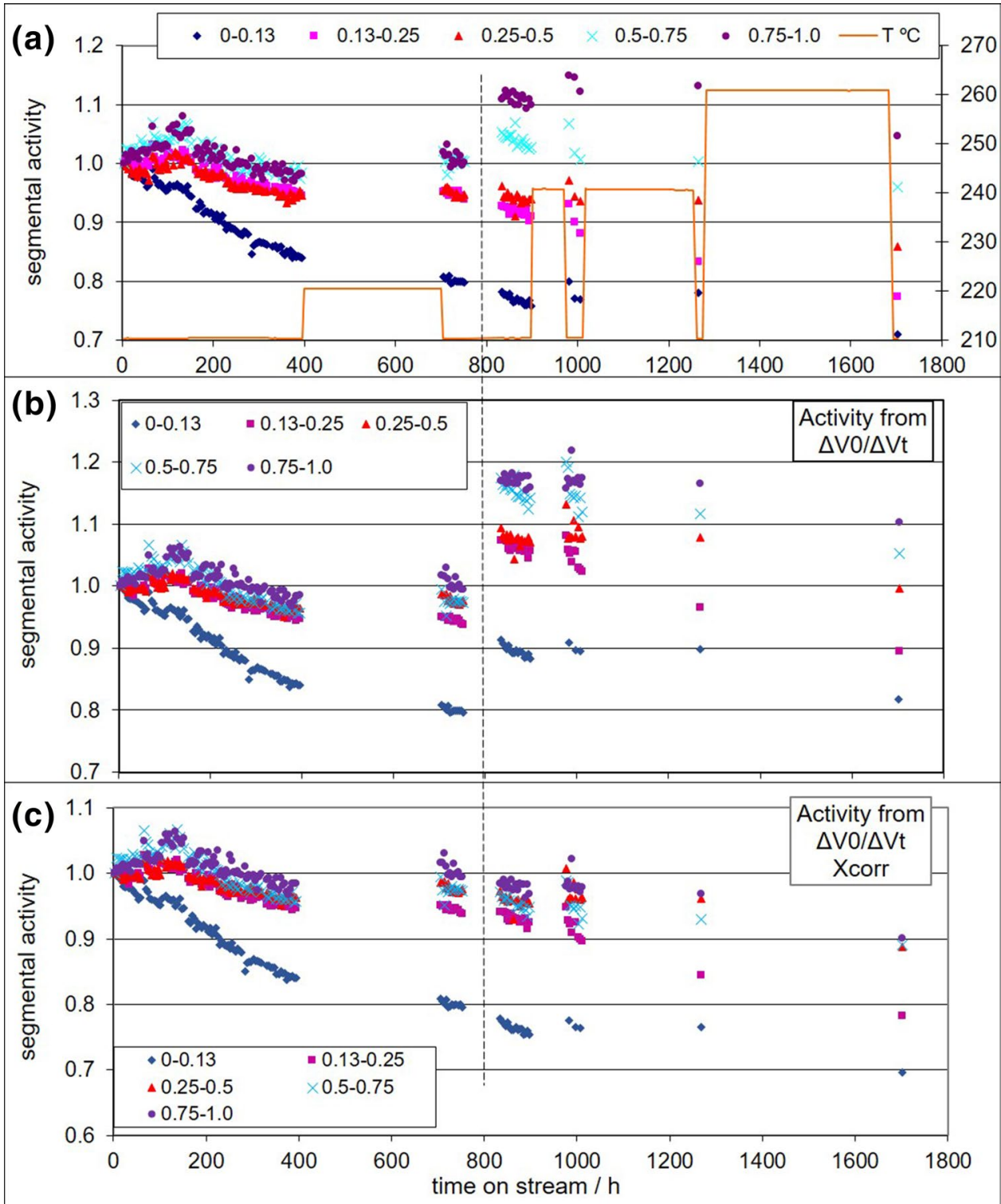
The corresponding trends determined by conversion parallel difference are shown in Fig. 14b. The activity values calculated by reference to the initial $\mathrm{V}-\mathrm{X}$ plot have been displaced by the step change in $\mathrm{H}_{2}$ /ester at $850 \mathrm{~h}$, but the trends are otherwise very similar to those in Fig. 14a. The $0.125-0.25$ segment apparently decayed more than other segments at $240{ }^{\circ} \mathrm{C}$, possibly indicating poison migration from the front segment. All segments decayed at $260{ }^{\circ} \mathrm{C}$. The segments $0.25-0.5,0.5-0.75$, and $0.75-1.0$ may all have decayed to the same extent, after allowing for the step change in $\mathrm{H}_{2}$ /ester ratio.

The step change in observed conversion values between 753 and $834 \mathrm{~h}$ for each catalyst bed can be seen in Fig. 3 . The magnitude of the change varied systematically with conversion. The $\Delta \mathrm{X}$ correction term is plotted against $\mathrm{X}$ in Fig. 15. The trend was fitted to a polynomial equation, which was used to correct observed values of $\mathrm{X}$ at $210{ }^{\circ} \mathrm{C}$ after the step change at $753 \mathrm{~h}$. The $\mathrm{H}_{2} /$ ester ratio will also affect the equilibrium conversion slightly, but this effect will be covered by the correction equation.

The deactivation trend in Fig. 14c for the corrected data from conversion parallel difference corresponds quite well to the trend from the reaction model in Fig. 14a. The empirical correction was more effective than the reaction model in correcting for the step-change for the bed segments in the rear half of the catalyst bed. All segments except for the top 0-0.125 segment showed remarkably similar trends in deactivation until $\sim 1300 \mathrm{~h}$. However, the data for the rear $0.75-1.0$ segment after $753 \mathrm{~h}$ might still be unreliable due to the high value of conversion. Figure $14 \mathrm{c}$ suggests that the deactivation rate in the $0.13-0.25$ segment increased more than in other segments during the long period at $240{ }^{\circ} \mathrm{C}$.

The apparent activation during the initial $150 \mathrm{~h}$ on stream appears broadly similar in Fig. 14a-c. It was noted earlier (see Fig. 9) that the degree of activation diverged in different bed segments at the start of the activation period. This could be a real effect or just a consequence of the general scatter in the data, magnified by the difference calculations. The evidence from detailed inspection of the data was inconclusive.

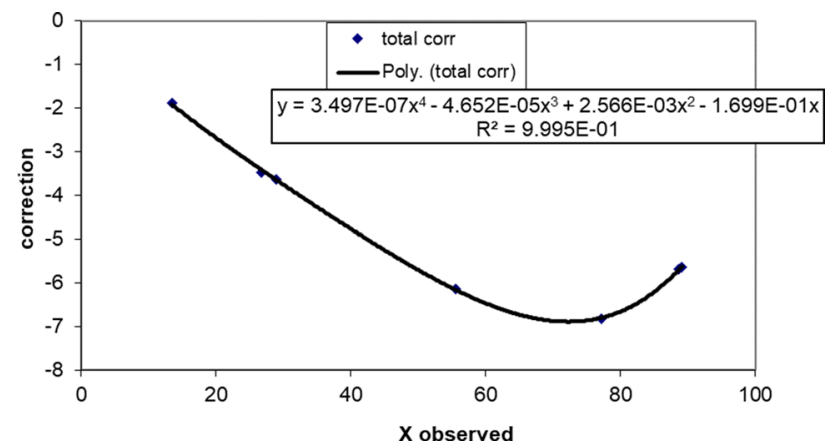

Fig. 15 Variation of conversion correction factor with conversion
The deactivation rate in the main part of the bed, especially the rear half, appeared to slow down from 800 to $1000 \mathrm{~h}$, behaviour typical of metal particle sintering. The deactivation rate appears to have increased again at $260{ }^{\circ} \mathrm{C}$, possibly approaching a new near plateau at each temperature.

\section{Discussion}

The main objective of this work was to provide evidence that the target industrial catalyst life was realistic. A secondary objective was to provide mathematical insight for development of a predictive model of catalyst deactivation. The parallel difference tests were complementary to a life test at larger scale.

The slowly declining conversion-time plots in Figs. 3 and 5 conceal overlapping processes of activation and deactivation. Three processes have been resolved by the parallel difference method, which was used to determine trends in mean activity for different segments of the catalyst bed. The results based on a pre-determined reaction model and, alternatively, on the axial conversion $(\mathrm{X}-\mathrm{V})$ profile at the start of the test, were broadly similar. The front $1 / 8$ th segment of the catalyst bed underwent a fast deactivation process, probably driven by chlorine and sulfur, which have both previously been shown to deactivate the $\mathrm{Cu} / \mathrm{ZnO}$ catalyst in this process, and are also well known to affect this type of catalyst in other processes. The deactivation in the front segment became faster after $150 \mathrm{~h}$. All other segments of the catalyst bed underwent a process of apparent activation from 0 to $140 \mathrm{~h}$, and this process was probably also occurring simultaneously with the fast deactivation in the front $1 / 8$ th bed. The nature of the activation process is unknown. It may have restarted for a period after the temperature was increased to $220^{\circ} \mathrm{C}$. An activation process has also been reported during the first $30 \mathrm{~h}$ of hydrogenation of ethyl acetate over $\mathrm{Cu} / \mathrm{C}$ catalysts at $180{ }^{\circ} \mathrm{C}$ [16]. A slow process of deactivation became evident after $150 \mathrm{~h}$ in all segments of the catalyst bed, except for the fast-deactivating top segment. The trend appeared to be broadly similar regardless of position in the bed, suggesting that the slow process was independent of the local composition of the fluid phase. Hence, it would be expected to be uniform also within the pores of a catalyst pellet, even with an intra-pellet composition gradient. This process became even slower after $800 \mathrm{~h}$. There is no obvious reason why it should speed up again unless the temperature is increased. This behaviour is characteristic of metal particle sintering, which has also previously been shown to deactivate the $\mathrm{Cu}$ / $\mathrm{ZnO}$ catalyst in this process and other processes. Although the trends would have been even better defined from longer tests, they do provide a basis for an initial estimation of the catalyst life, especially when combined with additional information from a test at larger scale. The trends of the 
individual processes of activation and deactivation, combined with knowledge of industrial feedstock purity, could also be used for an initial version of a deactivation model.

It was possible in this work to correct observed conversion values for a step change in feed composition after $753 \mathrm{~h}$, but usually the best policy in a deactivation test is to maintain constant feed composition. As well as making interpretation of activity data more difficult, any step change in composition might also affect the deactivation profile in the catalyst bed.

The original intention in this work was to evaluate segmental deactivation trends by parallel difference using the pre-determined reaction model. The data were also examined by Corella's point activity method which does not require a pre-determined reaction model. This method did not work well in practice, and resulted in noisy trends, as had already been found with another project. An analogous parallel difference method has also been examined with more success. The segmental deactivation trends were determined directly using the initial conversion profile, specifically the initial $\mathrm{V}-\mathrm{X}$ plot, to determine the corresponding $\Delta \mathrm{V}_{0}$ values for all later measurements of $\Delta \mathrm{X}$ and $\Delta \mathrm{V}$. This method worked very well in practice, and has the virtue of simplicity as it does not require a pre-determined reaction model. The method also worked well on another project, referred to earlier, although it was necessary to merge some segments which were too small for calculation of reliable conversion difference values.

The parallel difference method used in this case study worked well despite a few difficulties. The method requires precise and internally consistent data for reliable difference calculation of segmental activity values. Hence, the multitube parallel tests should be carried out with constant feedstock composition, feed rate and pressure and equi-diameter tubes with near isothermal axial and radial profiles. Duplicate or even triplicate tests with well-spaced catalyst quantities are desirable in order to avoid distortion of calculations by data scatter. The tests should include a very short bed (short space-time) so that the initial conversion profile is well determined and, later during the test, for detection of any narrow region of deactivation at the front of the catalyst bed. The combination of bed sizes $0.125,0.25,0.5,0.75$, and 1.0 in this study worked well. Smaller segments require more precise data compared to larger segments for determination of difference values. Alternatively, a statistical fitting over smaller segments could be tried.

The parallel difference method described above is applied to determination of the deactivation profile using measurements with decreasing conversion, constant flowrate and constant temperature.

Alternative parallel difference methods can also be used to determine the changing conversion profile with time. For instance, constant conversion can be maintained in the full-bed by progressively increasing temperature equally in all beds, simulating the constant conversion-increasing temperature strategy often used at industrial scale. However, an exact kinetic model would be required for determination of the changing activity profile, or alternatively, the tests could be returned periodically to the initial reference temperature as in this work. Further insight can be gained from additional parallel tests carried out at higher temperature or, as in this work, with temperature sequencing, or by separating duplicate tests for this purpose after the initial behaviour has been determined $[3,4,8]$.

Acknowledgements Thanks are due to BP International Limited for funding the original research for the ester hydrogenation process, and to Les Bolton of BP for his contribution to the original development of the process, to INEOS Acetyls UK, the owner of the Intellectual Property, to Rob Berger of Anaproc.com for advice on radial thermal conductivity in catalyst beds, and to the University of Glasgow for granting an honorary position to John Birtill.

Author Contributions Not applicable.

Funding The experimental study in this paper was funded by BP International Limited.

Data Availability (data transparency) Not applicable.

Code Availability Not applicable.

\section{Declarations}

Conflict of interest Not applicable.

Consent to Participate Authors have given consent.

Consent for Publication Approved by INEOS Acetyls UK.

Open Access This article is licensed under a Creative Commons Attribution 4.0 International License, which permits use, sharing, adaptation, distribution and reproduction in any medium or format, as long as you give appropriate credit to the original author(s) and the source, provide a link to the Creative Commons licence, and indicate if changes were made. The images or other third party material in this article are included in the article's Creative Commons licence, unless indicated otherwise in a credit line to the material. If material is not included in the article's Creative Commons licence and your intended use is not permitted by statutory regulation or exceeds the permitted use, you will need to obtain permission directly from the copyright holder. To view a copy of this licence, visit http://creativecommons.org/licenses/by/4.0/.

\section{References}

1. Twigg MV, Spencer MS (2001) The deactivation of supported copper metal catalysts for hydrogenation reactions. Appl Catal A 212(1-2):161-174. https://doi.org/10.1016/S0926-860X(00) 00854-1

2. Levenspiel O (1972) Chemical reaction engineering (ch 15), 2nd edn. Wiley, New York 
3. Birtill JJ (2003) But will it last until the shutdown? Deciphering catalyst decay! Catal Today 81:531-545. https://doi.org/10.1016/ S0920-5861(03)00152-4

4. Birtill JJ (2007) Measurement and modeling of the kinetics of catalyst decay in fixed beds: the Eurokin survey. Ind Eng Chem Res 46(8):2392-2398. https://doi.org/10.1021/ie060590v

5. Wilkinson SK, Simmons MJH, Stitt EH, Baucherel X, Watson MJ (2013) A novel approach to understanding and modelling performance evolution of catalysts during their initial operation under reaction conditions. Case study of vanadium phosphorus oxides for n-butane selective oxidation. J Catal 299:249-260. https://doi. org/10.1016/j.jcat.2012.11.027

6. Wilkinson SK, van de Water LGA, Miller B, Simmons MJH, Stitt $\mathrm{EH}$, Watson MJ (2016) Understanding the generation of methanol synthesis and water gas shift activity over copper-based catalysts - A spatially resolved experimental kinetic study using steady and non-steady state operation under $\mathrm{CO} / \mathrm{CO} 2 / \mathrm{H}-2$ feeds. J Catal 337:208-220. https://doi.org/10.1016/j.jcat.20

7. van de Water LGA, Wilkinson SK, Smith RAP, Watson MJ (2018) Understanding methanol synthesis from $\mathrm{CO} / \mathrm{H}-2$ feeds over $\mathrm{Cu} /$ $\mathrm{CeO} 2$ catalysts. J Catal 364:57-68. https://doi.org/10.1016/j.jcat. 2018.04.026

8. Birtill JJ (2018). What progress in catalyst deactivation? Eurokin 20th anniversary symposium. Maastricht. www.Eurokin.org

9. WO $2015 / 097086$ to BP plc (2013). US Patent $9,975,828$ to BP plc (2015).
10. NIST Chemistry WebBook https://webbook.nist.gov/

11. Corella J, Asua JM, Bilbao J (1980) Kinetics of the deactivation of a $10 \%$ copper- $0.5 \%$ chromia/asbestos catalyst for benzyl alcohol dehydrogenation. Chem Eng Sci 35(6):1447-1449

12. Mears DE (1971) Tests for transport limitations in experimental catalytic reactors. Ind Eng Chem Process Des Dev 10(4):541-547. https://doi.org/10.1021/i260040a020

13. Mears DE (1971) Diagnostic criteria for heat transport limitations in fixed bed reactors. J Catal 20:127-131

14. Pérez-Ramirez J, Berger RJ, Mul G, Kapteijn F, Moulijn JA (2000) The six-flow reactor technology: a review on fast catalyst screening and kinetic studies. Catal Today 60(1-2):93-109. https://doi. org/10.1016/S0920-5861(00)00321-7

15. EUROKIN Fixed Bed Webtool Guide. https://eurokin.org/Tools

16. Beerthuis R, de Rijk JW, Deeley JMS, Sunley GJ, de Jong KP, de Jongh PE (2020) Particle size effects in copper-catalyzed hydrogenation of ethyl acetate. J Catal 388:30-37. https://doi.org/10. 1016/j.jcat.2020.05.006

Publisher's Note Springer Nature remains neutral with regard to jurisdictional claims in published maps and institutional affiliations. 